\title{
Are Wet-Induced Wrinkled Fingers Primate Rain Treads?
}

\author{
Mark Changizi Romann Weber Ritesh Kotecha Joseph Palazzo
}

2AI Labs, Boise, Idaho, USA

\section{Key Words}

Animal behavior $\cdot$ Evolution · Skin

\begin{abstract}
Wet fingers and toes eventually wrinkle, and this is commonly attributed by lay opinion to local osmotic reactions. However, nearly a century ago surgeons observed that no wrinkling occurs if a nerve to the finger has been cut. Here we provide evidence that, rather than being an accidental side effect of wetness, wet-induced wrinkles have been selected to enhance grip in wet conditions. We show that their morphology has the signature properties of drainage networks, enabling efficient removal of water from the gripped surface.

Copyright $\odot 2011$ S. Karger AG, Basel
\end{abstract}

Fingers and toes wrinkle (fig. 1) if soaked in water for around $5 \mathrm{~min}$ [Cales and Weber, 1997], and this phenomenon is commonly attributed in lay opinion to local osmotic interactions. However, it has long been known that cuts to sympathetic innervation to a finger abolish the wrinkling response to wetness [Lewis and Pickering, 1936; O’Riain, 1973; Bull and Henry, 1977; Braham et al., 1979; Alvarez et al., 1980; Vasudevan et al., 2000; Hsieh et al., 2006, 2007; Tindall et al., 2006], which has led to suggestions to use the wrinkling response as a simple test for sympathetic integrity in unresponsive patients. For example, Vasudevan et al. [2000] showed that blocking the sympathetic response, either temporarily via lumbar epidural infusion or permanently via chemical or surgical cervical sympathectomy, terminated the wet-wrinkling
Fig. 1. Wet-induced wrinkles on the first author's fingertips (a) and a young macaque monkey (b).
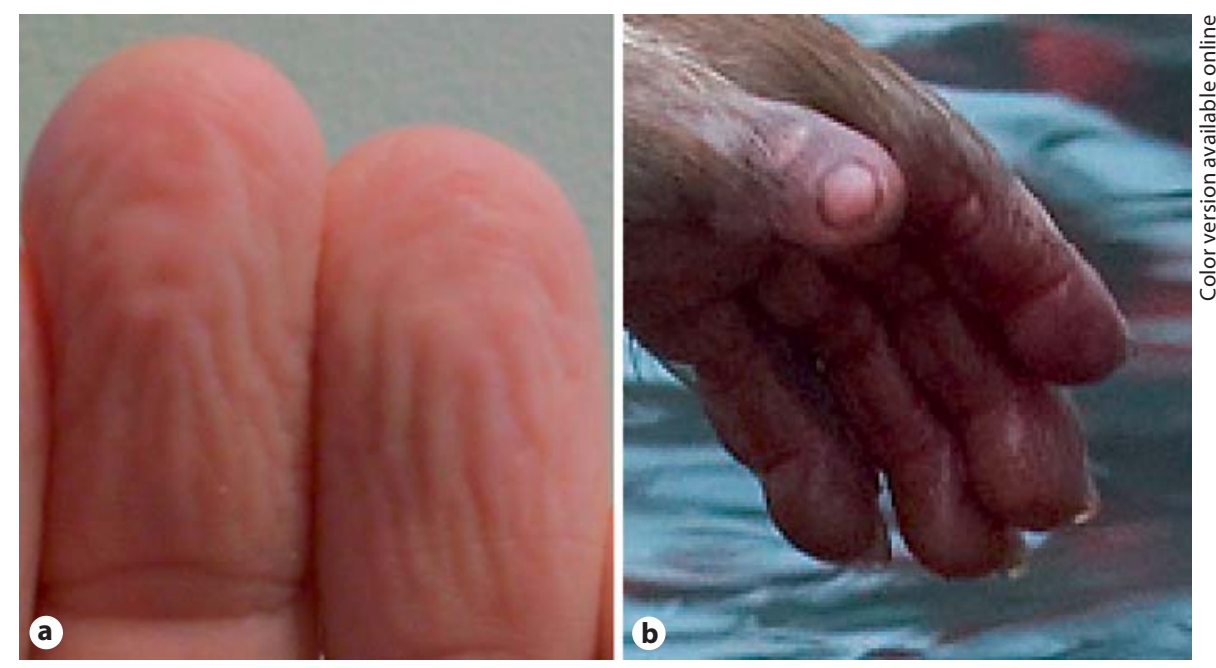

\section{KARGER}

Fax +4161306 1234

E-Mail karger@karger.ch

www.karger.com
(C) 2011 S. Karger AG, Basel

0006-8977/11/0774-0286\$38.00/0

Accessible online at:

www.karger.com/bbe
Mark Changizi

2AI Labs

917 Lusk St, Ste 369

Boise, ID 83706 (USA)

E-Mail changizi@2ai.org 
Fig. 2. Smooth tires such as the racing tire (left) provide the best grip in dry conditions. In wet conditions, however, rain treads (right) are better. Here, we explore the hypothesis that, although smooth fingertips provide the best grip in dry conditions, fingertips wrinkle in wet conditions for better grip, akin to rain treads.
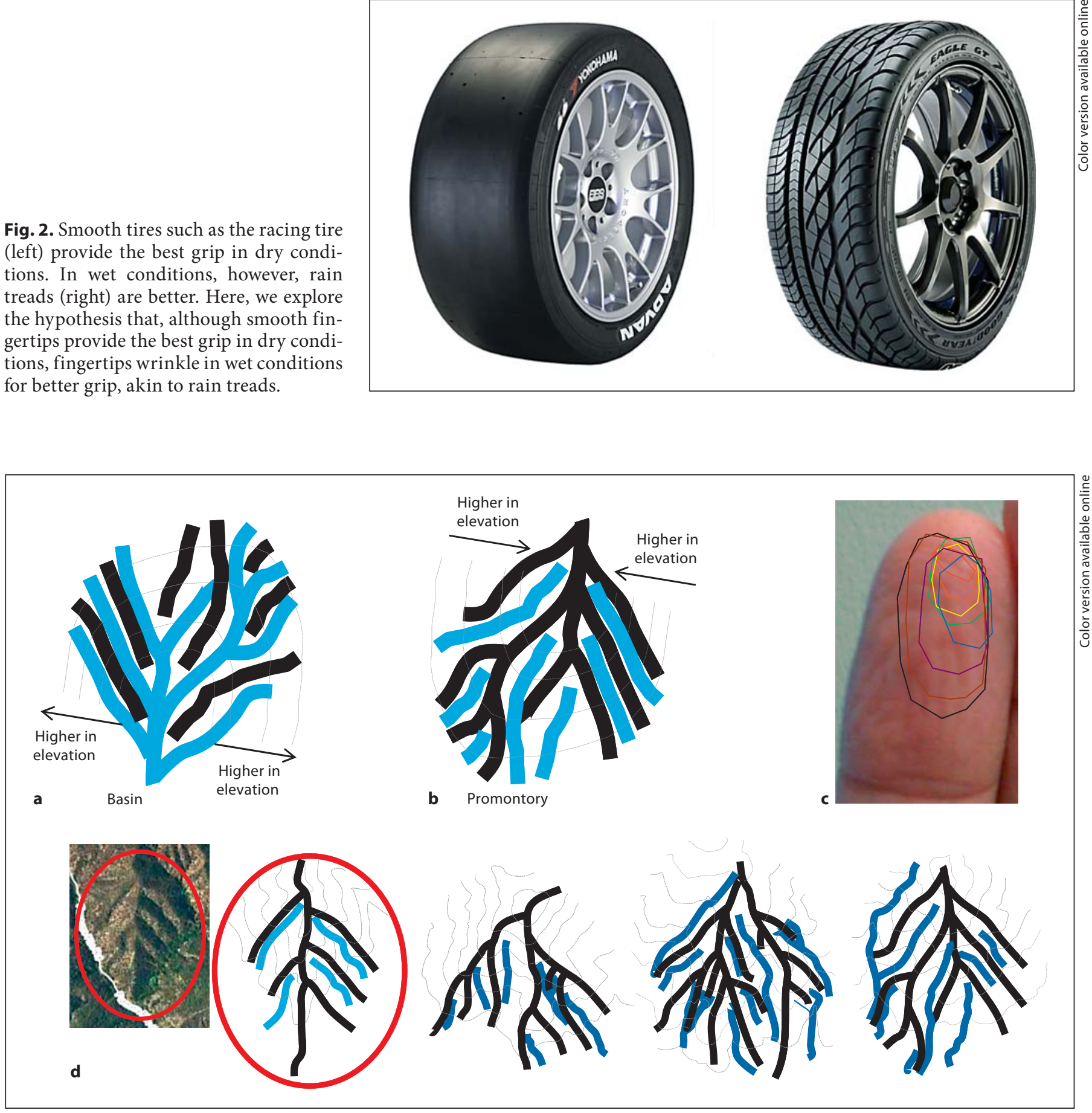

Fig. 3. Predicted shape of wet-induced wrinkles if they have been selected for water drainage during grip. Example of channels (light blue; color refers to online version only), divides (black), and iso-elevation contours for a concave basin (a) and a convex promontory (b). The relevant topography for a finger grip is a convex promontory where the peak is the initial point of grip contact and later regions of contact are at a lower 'elevation'. c Isopressure contours for fingers pressing down on glass, frame by frame, during a video. Because a convex topography applies to grip, finger wrinkles are expected to have the signature morphology indicated in b. d Example drainage networks on convex mountain promontories (in Southern California) illustrating the signature features in $\mathbf{b}$. The leftmost network shows the aerial photo on its left. Topographic maps and aerial photos were obtained from www.digital-topo-maps.com, and their locations are, respectively, at the coordinates $(34.1249,-118.5229),(34.7265$, $-117.0976)$, (34.6341, -117.0728), and (34.6630, -117.1400). 


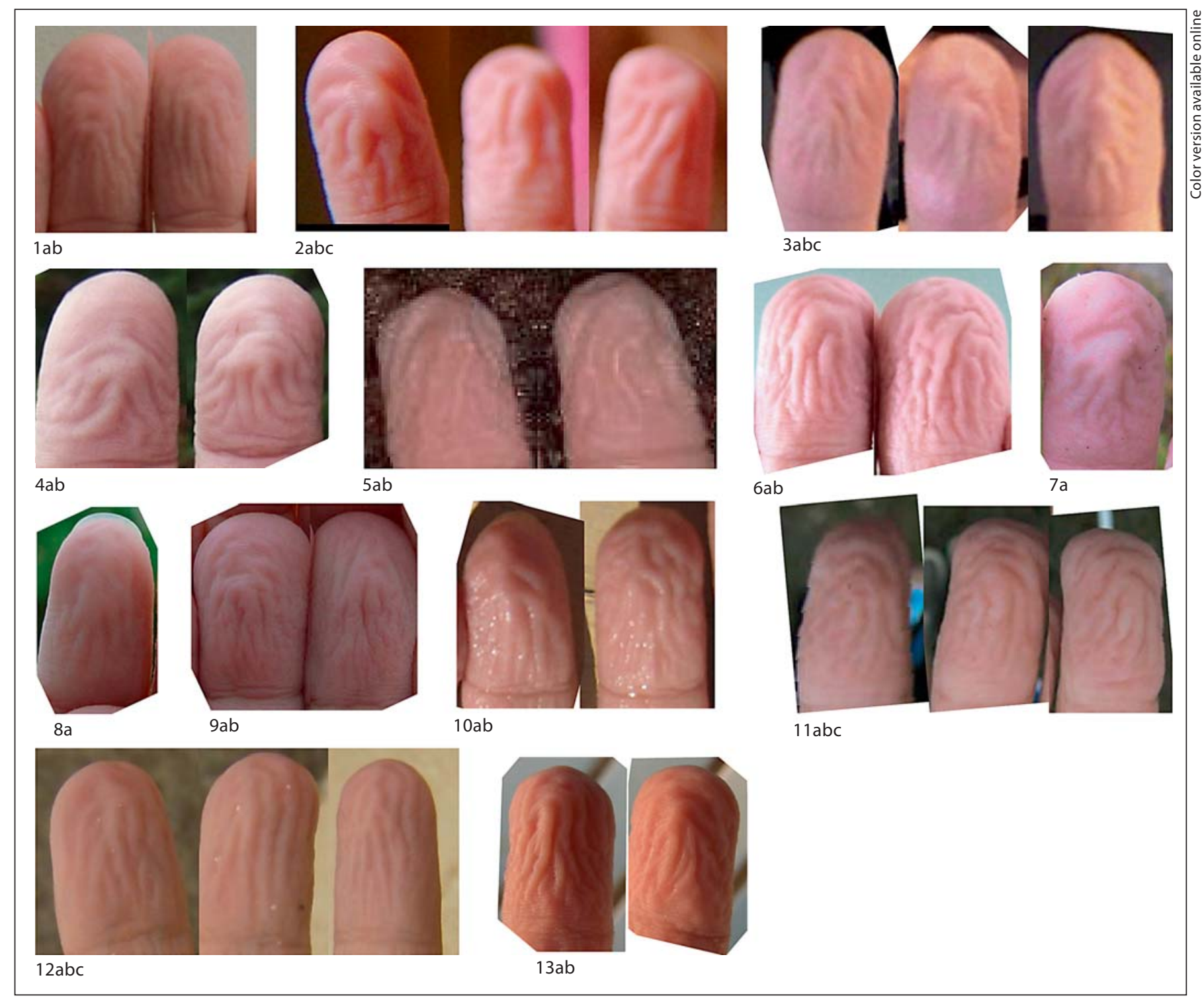

Fig. 4. Wet-wrinkle networks on 28 fingers from 13 hands. These were found in the public online domain and were kept so long as the image was sufficiently sharp to see the wrinkles.

response. Wilder-Smith [2004] provides evidence that the finger-wrinkling mechanism may be due to digit pulp vasoconstriction: wet-induced wrinkles are accompanied by vasoconstriction [Wilder-Smith and Chow, 2003a], and wrinkles are induced by vasoconstrictive agents [Wilder-Smith and Chow, 2003b; Wilder-Smith, 2004].

That the wet-wrinkling response is neurally mediated motivated us to ask whether wrinkles may serve an adaptive function in wet conditions. Here we provide evidence for a 'rain tread' hypothesis (fig. 2) that wet-induced fin- ger and toe wrinkles are drainage networks for channeling away water during grip in wet conditions (such as rain or dew), thereby allowing primates to maintain a good grip.

The most familiar kind of drainage network is that found in river basins, where the river channels flow toward one another into larger 'parent' channels, resulting in a tree where the 'trunk' is the largest downstream channel, as illustrated in figure 3a. The divides, on the other hand, are disconnected and diverge away from one 


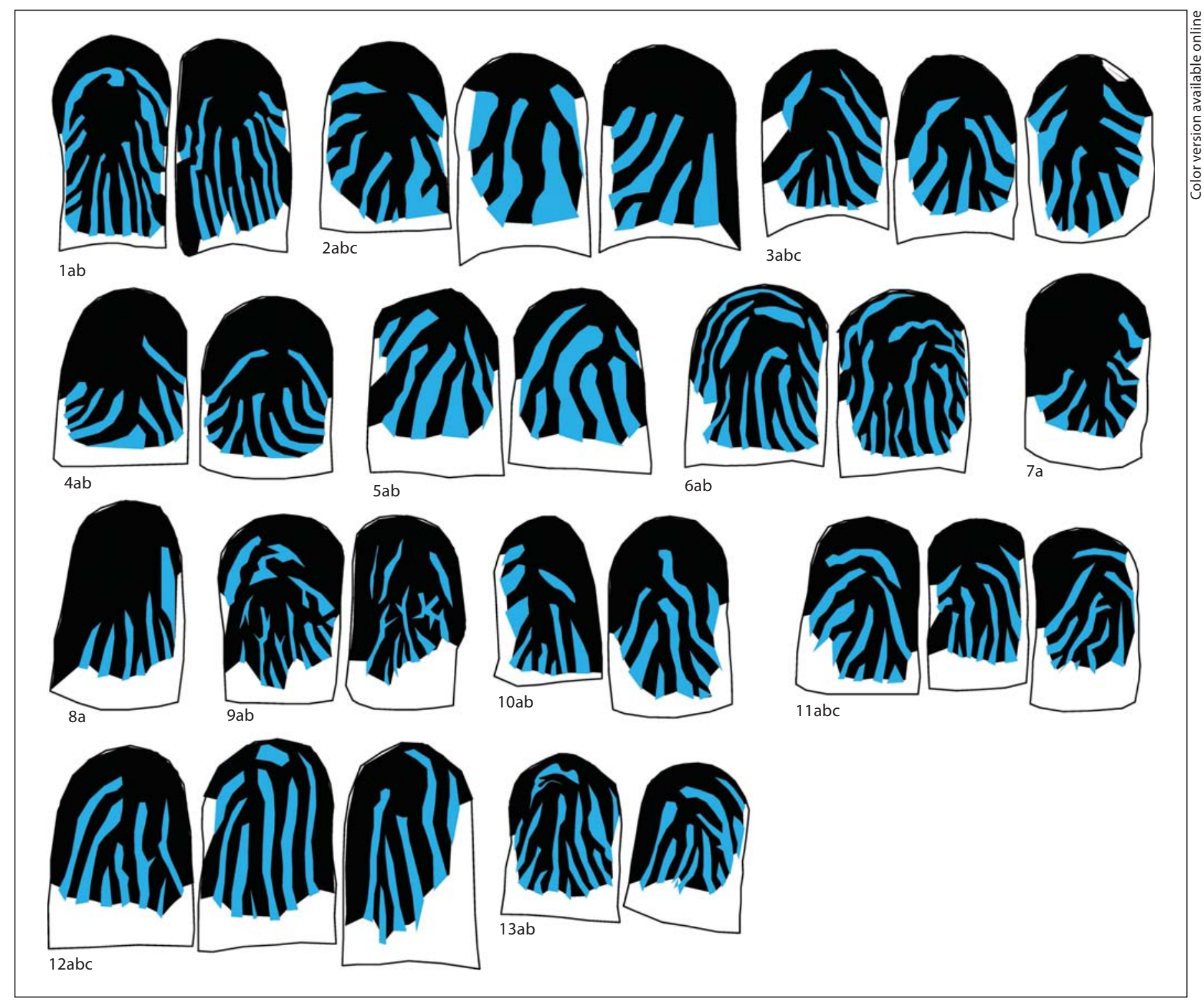

Fig. 5. Channel-like troughs in finger wrinkles (light blue; color refers to online version only), and the borders between them (black), for the fingers in figure 4. The signature of a drainage network on a convex promontory (see fig. $3 \mathrm{~b}, \mathrm{~d}$ ) is readily apparent; disconnected channels diverge from one another away from the peak, and divides form a connected tree with its root at the peak.

another uphill. However, drainage networks are dramatically different in topographies such as convex promontories, where roughly the 'opposite' is found: the channels are disconnected from one another and diverge away from one another downhill, and divides link together to form a tree with its trunk at the promontory's peak (fig. 3b).

If wet-induced wrinkles are drainage networks as we hypothesize, then, because the compression topography for fingertips is that of a promontory (fig. 3c), wet wrin-

Are Wet-Induced Wrinkled Fingers

Primate Rain Treads? kles are predicted to have, like the illustration in figure $3 \mathrm{~b}$, disconnected channels that diverge away from one another downstream and divides (or borders between the channels) that form a tree with its root near the peak of the compression topography. Figure $3 \mathrm{~d}$ shows example promontory networks on mountains having these characteristics.

Figure 4 shows wet-induced wrinkle networks from 28 fingers of 13 hands, and figure 5 indicates the channellike depressions (in light blue) and divides (in black). One 
can immediately see that they possess the signature structure of drainage networks on convex promontories (like in fig. 3b, d). Namely, the channel-like wrinkle depressions tend to be disconnected from one another and diverge away from one another as they get more distant from the 'peak' near the fingertip; the divides (or borders between the channels) are connected, forming a tree with its root near the fingertip.

These wrinkle structures not only have the signature of a convex promontory drainage network but more specifically are also consistent with the pressure topography in figure 3c. The finger topography has 'cliffs' on all sides except for that of the palm, where there is a long slope. Consistent with this topography, nearly all of the channel structure in finger wrinkles is found in this long sloping 'mountain side' (i.e. little or no channel structure is expected on cliffs).

As in other cases of 'biological trees' [Cherniak et al., 1999; Changizi and Cherniak, 2000; Changizi, 2001], wet-wrinkle drainage networks may be near optimal, although here we have not attempted to gauge this.

Wet-induced wrinkles may, in fact, be substantially superior to 'rain treads' on shoes, which maintain a tread even when under compression and thus have a surface area of contact that is reduced. Wet-induced wrinkle treads, on the other hand, are pliable, and the act of press- ing a finger tip down on a wet surface 'squeezes' the fluid out from under the finger through the channels, and upon completion of this single pulsatile flow the entire finger's skin contacts the surface.

In addition to wet-induced finger wrinkles having the signature morphology of drainage networks, the time scale at which they appear (around $5 \mathrm{~min}$ ) [Cales and Weber, 1997] is plausibly appropriate for natural wet conditions; it is fast enough to be relevant for dew or rainy conditions but not so quick that casual contact with water (like when eating fruit) will elicit it. Wrinkling also occurs most quickly under hypotonic conditions [Tsai and Kirkham, 2005], consistent with the freshwater (rain and dew) wet conditions relevant to primate grip. Moreover, of course, the fact that wet wrinkles happen nowhere else on the body except on the fingers and feet is consistent with this rain tread hypothesis.

In the future, we hope to carry out (i) behavioral studies to see whether wrinkled fingers are superior to nonwrinkled fingers in wet conditions, and (ii) comparative studies to learn which mammals show the phenomenon (we currently only possess evidence for humans and macaques; fig. 1) and whether grasping mammals in wetter habitats are more likely to possess the mechanism.

\section{References}

-Alvarez G, Eurolo J, Canales P (1980): Finger Cherniak C, Changizi MA, Kang D (1999): wrinkling after immersion in water. Br Med J 281:585-586.

Braham J, Sadeh M, Saravoa-Pinhas I (1979): Skin wrinkling on immersion of hands: a test of sympathetic function. Arch Neurol 36: $113-114$.

Bull C, Henry JA (1977): Finger wrinkling: a test of autonomic function. Br Med J 1:551-552.

Cales L, Weber RA (1997): Effects of water temperature on skin wrinkling. J Hand Surg Am 22:747-749.

Changizi MA (2001): The economy of the shape of limbed animals. Biol Cybern 84:23-29.

Changizi MA, Cherniak C (2000): Modeling the large-scale geometry of human coronary arteries. Can J Physiol Pharmacol 78:603-611. Large-scale optimization of neuron arbors. Phys Rev E Stat Phys Plasmas Fluids Relat Interdiscip Topics 59:6001-6009.

Hsieh CH, Huang KF, Liliang PC, Huang PC, Shih HM, Rau CS (2007): EMLA and water immersion cause similar vasodilatation in replanted fingers. J Surg Res 143:265-269.

Hsieh CH, Huang KF, Liliang PC, Jeng SF, Tsai HH (2006): Paradoxical response to water immersion in replanted fingers. Clin Auton Res 16:223-227.

Lewis T, Pickering GW (1936): Circulatory changes in fingers in some diseases of the nervous system, with special reference to digital atrophy of peripheral nerve lesions. Clin Sci 2:149.

O'Riain S (1973): A new and simple test of nerve function in hand. Br Med J 3:615-616.

Tindall A, Dawood R, Povlsen B (2006): Case of the month: the skin wrinkle test - a simple nerve injury test for paediatric and uncooperative patients. Emerg Med J 23:883-886.
Tsai N, Kirkham S (2005): Fingertip skin wrinkling - the effect of varying tonicity. J Hand Surg Br 30:273-275.

-Vasudevan TM, van Ru AM, Nukada H, Taylor PK (2000): Skin wrinkling for the assessment of sympathetic function in the limbs. Aust NZ J Surg 70:57-59.

Wilder-Smith EP (2004): Water immersion wrinkling: physiology and use as an indicator of sympathetic function. Clin Auton Res 14:125-131.

-Wilder-Smith EP, Chow A (2003a): Water immersion and EMLA cause similar digit skin wrinkling and vasoconstriction. Microvasc Res 66:68-72.

-Wilder-Smith EP, Chow A (2003b): Water-immersion wrinkling is due to vasoconstriction. Muscle Nerve 27:307-311. 